\title{
Long-Term Trend of Climate Change and Drought Assessment in the Horn of Africa
}

\author{
Mihretab G. Ghebrezgabher, ${ }^{1,2}$ Taibao Yang, ${ }^{1}$ and Xuemei Yang ${ }^{3}$ \\ ${ }^{1}$ Institute of Glaciology and Eco-Geography, College of Earth and Environmental Sciences, Lanzhou University, \\ Lanzhou 730000, China \\ ${ }^{2}$ Eritrea Institute of Technology, College of Education, Mai-Nefhi 12676, Eritrea \\ ${ }^{3}$ Gansu Desert Control Research Institute, Lanzhou 730070, China
}

Correspondence should be addressed to Taibao Yang; yangtb@lzu.edu.cn

Received 6 August 2016; Accepted 23 October 2016

Academic Editor: Hiroyuki Hashiguchi

Copyright (C) 2016 Mihretab G. Ghebrezgabher et al. This is an open access article distributed under the Creative Commons Attribution License, which permits unrestricted use, distribution, and reproduction in any medium, provided the original work is properly cited.

\begin{abstract}
Climate change due to global warming is a world concern, particularly in Africa. In this study, precipitation and temperature variables are taken as a proxy to assess and quantify the long-term climate change and drought in the Horn of Africa (HOA) (19302014). We adapted a simple linear regression and interpolation to analyze, respectively, the trend and spatial distribution of the mean annual precipitation and temperature. In addition, standardized precipitation evapotranspiration index (SPEI) was applied to evaluate the drought condition of the HOA. The results revealed that statistically the trend of precipitation decreased insignificantly; the trend of temperature was observed to drop very significantly between 1930 and 1969, but it was dramatically elevated very significantly from 1970 to 2014 . The SPEI showed that the HOA experienced from mild to moderate drought throughout the study period with severe to extreme drought in some regions, particularly in 1943, 1984, 1991, and 2009. The drought was a very serious environmental problem in the HOA in the last 85 years. Thus, an immediate action is required to tackle drought and hence poverty and famine in the HOA.
\end{abstract}

\section{Introduction}

Climate change is a global concern, particularly, with increase in the rate of mean temperature and decline of annual mean precipitation [1]. Today, climate warming is a global concern. Climate hazard grows with increase warming $[2,3]$ and vegetation production is declining in response to climate warming [4], particularly in desert vegetation [5]. Longterm change in the average weather patterns may refer to climate change; the change might be quantitatively and qualitatively; however, the statistical analysis is the most suitable and commonly applied analysis to stress short- or longterm trend of precipitation and temperature changes $[2,6$, 7]. According to the United State Environmental Protection Agency (EPA) (https://www3.epa.gov/climatechange/ basics/), the mean temperature of the Earth's surface increased by $1.5^{\circ} \mathrm{F}$ in the last one hundred years, and it will be raised by 0.5 to $8.6^{\circ} \mathrm{F}$ in the next century.
Climate change is directly or indirectly caused by anthropogenic or natural factors. Anthropogenic factors may be related to emission of various gases from industries and vehicles, leading to increase in amount and concentration of natural greenhouse gases in the atmosphere such as carbon dioxide $\left(\mathrm{CO}_{2}\right)$, methane gas $\left(\mathrm{CH}_{4}\right)$, Chlorofluorocarbons (CFCs), and nitrous oxide (NO) [2, 6, 7]; particularly, the rise of $\mathrm{CO}_{2}$ in the atmosphere is the main factor to increase warming on the Earth's surface [8]. Land use changes, including clearing of forests for different purposes (e.g., farming, firewood, industrial and medical material, construction, and urbanization). Generally, directly or indirectly deforestation, desertification, overgrazing, and modernization might accelerate global warming $[2,6,9]$. According to Food and Agricultural Organization/Global Forest Resources Assessment (FAO/FRA) 2015 [10] globally, the forest cover has been decreasing despite an increase in planted forests since 1990, and this might lead to increase in the concentration of $\mathrm{CO}_{2}$ in 
the atmosphere. Climate warming may occur due to natural factors such as variations in solar radiation. The presence of aerosols in the Earth's atmosphere either from a volcanic eruption or from other materials may cause climate warming by absorbing or scattering the solar radiations, and it may change chemical and physical prosperities of clouds that lead to global warming $[2,6]$.

In general, an increase in temperature on the Earth's surface is leading to changes in rainfall distribution and frequency, drought and flooding, melting of glaciers, lowering of ice cover in the arctic region, and decrease of snow in terms of amount, frequency, and intensity, which are the main indicators of climate change. Climate change is serious in the Horn of Africa (HOA); several researchers found that the annual mean temperature and precipitation were, respectively, raised and declined in the Sub-Saharan African countries in general [1] and in the HOA in particular [11]. Drought and flooding are serious natural disasters in this region, mainly, drought is severe since the 1970s [12, 13], according to African Development Bank (ADB) 2011 [14], millions of people and livestock were under serious food crises in the HOA, and climate change led the region to be one of the poorest regions in the world where above $50 \%$ of the population is living below the poverty line. Recently, several researchers [15-17] have found that drought frequently occurs during El Nino periods, including the HOA.

Climate change might have positive or negative consequences. However, the adverse effects of climate change are more thoughtful, which are the concern of the entire globe. Climate change causes environmental, social, economic, and political stresses from local to global scales [18], many species of animals and plants have been extinct, tens of thousands of human lives were lost due to heat wave, drought, flooding, and so forth, declining economic growth at local and regional/national levels, which affect millions of people in the world, waiting for international/national aids in every climate-related disaster, and climate change might cause local and tribal conflict [8] and change in ecosystem and biodiversity [19]. Soil moisture lowers as a result of high rate of evaporation and soil erosion is serious with climate change, leading to decrease in vegetation cover $[3,20]$. In the HOA, environmental, social, economic, and political issues due to change of climate and weather patterns are very obvious; for instance, drought is serious environmental disaster in this region, particularly in Ethiopia and Eritrea, which affected thousands of people in 1980s [12, 21]. During drought period, resources are scarce, leading to conflict among local people; recently researchers have found that local conflict was recorded in Sub-Saharan Africa, mainly in the HOA because of climate change [22, 23]. In 2011 [24], the Institute for Environmental Security (IES) had reported that conflict and migration are extremely serious in the HOA, especially during drought periods [25]. In this region, above $80 \%$ of the population engage in rain-fed agriculture and herding at a very low production [7, 11, 26, 27]; thus poverty is extremely high although they are enjoying a little economic growth in the last 10 years. In the future, drought and flooding will be expected to continue in the HOA because temperature is expected to rise in the next century $[2,25]$.
Climate change is very active and serious in the HOA, and several types of researches have been done in Eastern Africa including the HOA in particular. Therefore, this paper aimed to provide an assessment of long-term climate change in this region from 1930 to 2014; precipitation and temperature variabilities are used as a proxy to evaluate the statistical trend of climate change. In addition, drought was analyzed using Standardize Precipitation Evapotranspiration Index (SPEI). We believe this study would be significant for decision makers to develop an effective plan to solve food insecurity in the HOA and it might be a useful input for researchers, who are interested in this region for further study.

\section{The Study Area}

The HOA is situated in Eastern Africa, including Ethiopia, Somalia, Djibouti, Eritrea, and parts of Kenya, Uganda, Tanzania, and Sudan $[28,29]$. However, this study covers only the first four countries and Kenya; in this study, the HOA extends from $18^{\circ} \mathrm{N}$ in Eritrea to Kenya $5^{\circ} \mathrm{S}$ and from Ethiopia $32^{\circ} \mathrm{E}$ to Somalia $51^{\circ} \mathrm{E}$ (Figure 1). This region covers approximately $2,509,678 \mathrm{~km}^{2}$, where Ethiopia is the largest country and the smallest one is Djibouti. The region has about 164.45 million population. The HOA is bordered with two big water bodies, the Red Sea and the Indian Ocean, respectively, on the coast of Eritrea and Djibouti and Somalia and Kenya, but Ethiopia is the only landlocked country in this study. Topographically the HOA is very complex, including mountains, valleys, rifts, rivers, ridges, and lakes. The greatest rift in the world (Eastern Great Rift) is located in this region, and earthquake and a volcanic eruption are active [30]; the volcanic eruption of 2010 that occurred in the Danakil depression of Ethiopia and Eritrea is a good example. The elevation of HOA ranges from the highlands of Ethiopia to the Danakil depression below sea level; the Danakil depression (local name Dallol) is the hottest place on the surface of the Earth $\left(>60^{\circ} \mathrm{C}\right)$. Lake Tana, Lake Abaya, Lake Turkana, and a small part of Lake Victoria are the biggest surface water located in the HOA along the rift valley $[17,28,30,31]$. The Lake Tana in Ethiopia is the source of Blue Nile River, which is a tributary of the Nile River [32]. Drought due to climate change and land gradation are the major environmental concerns of this region.

2.1. Meteorological Stations. Precipitation and temperature variabilities were applied to evaluate long-term climate change in the HOA. Weather data directly from a rain gauge is suitable to have an accurate and reliable climate analysis. However, the rain gauges in the Sahel region have a lack of consistency and are not appropriate [33]. In this study, we selected 48 meteorological stations from inside and outside of the study area and we obtained the latitude, longitude, and elevation of each of the actual weather stations from the National Oceanic and Atmospheric Administration (NOAA) at http://gis.ncdc.noaa.gov/map/viewer/\#app= clim \&cfg $=$ cdo\&theme $=$ hourly\&layers $=1 \&$ node $=$ gis. Terres trial precipitation and temperature (1930-2014) were collected from a gridded monthly time series (version 4.01) available in May 2015, which was interpolated by $0.25 \times 0.25$ degrees of resolutions. In addition, the degree of resolution is 


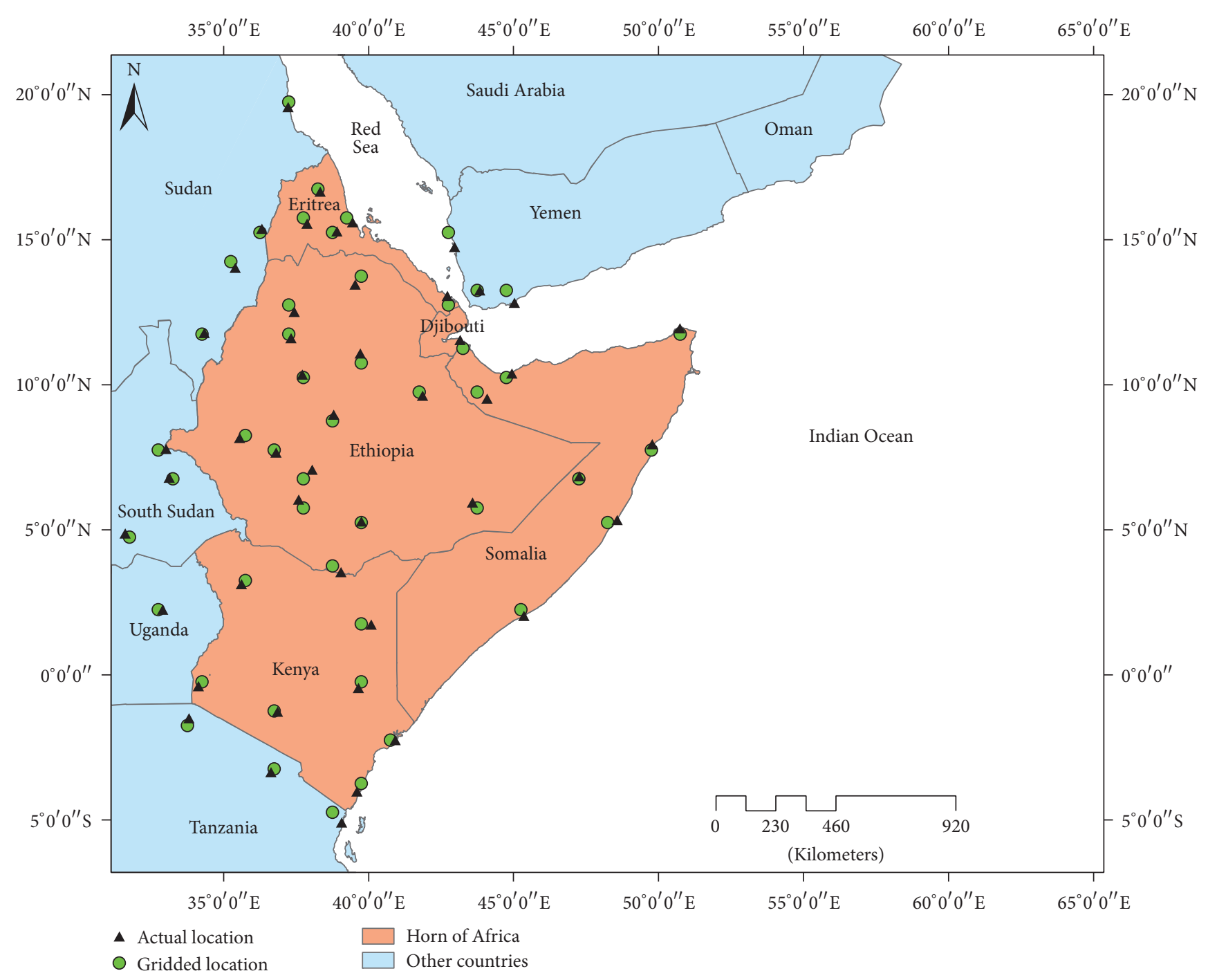

FIGURE 1: The selected locations of actual and gridded meteorological stations in the HOA.

available only at an interval of 0.25 and 0.75 ; thus, the latitudes and longitudes of the gridded stations were selected to the closest point (Figure 1). In this version, the meteorological data were collected from several updated sources such as Global Historical Climatology Network dataset (GHCNmonthly and GHCN-Daily) and other data including environment Canada archive, data from the hydrometeorological institute in St. Petersburg, Russia, Greenland station records from the automatic weather station project, daily data for India from the National Center for Atmospheric Research (NCAR), Nicholsons archive of African precipitation data, South American monthly precipitation station records, and daily records from the Global Surface Summary of Day (GSOD) [34].

2.2. Data Processing and Testing. In a time series study, meteorological data processing and homogeneity testing are very crucial to assess and evaluate climate change. Daily or monthly meteorological data at a station or at a gridded point might be not uniform because of several factors. The data can be certainly influenced by the quality of the instrument, building, trees, changing the location of observation, and recording errors [35]. Heterogeneous meteorological data is biased and influences reliability and consistency of climate change such as precipitation and temperature data. In order for decision makers to develop a good plan to manage and control the environment, in general, meteorological data such as daily or monthly precipitation and temperature must be homogeneous to enhance reliability and accuracy of the study.

Despite a number of methods developed to test meteorological data, in this study, a Rainbow software package (version 2.2) was applied to analyze the homogeneity of the time series precipitation and temperature data at the gridded station. The Rainbow frequency analysis was developed by Raes et al., 2006 [36], and, recently, several researchers have applied it in their meteorological study [37-39]. A normal distribution of probability, Weibull method of estimating the probability, and maximum likelihood method of parameter estimation were adopted for this study where a 
threshold is considered as nil/zero for all observations. Upon testing, an overestimation of precipitation has appeared in Massawa station (39.25 and 15.75), which is very crucial. According to Ministry of Land, Water and Environment (MLWE) in Eritrea 2012, annually this area receives the lowest rainfall $(<200 \mathrm{~mm})$; however, the highest annual precipitation is estimated by version 4.01 . In order to minimize errors and enhance accuracy, we collected monthly precipitation for Massawa station from Koninklijk Nederlands Meteorologisch Instituut (KNMI) Climate Explorer at http://climexp.knmi.nl/getstations.cgi (1930-1990), and then a linear regression was applied to adjust the data.

\section{Methodology}

3.1. Trend and Interpolation Methods. Interpolation and trend methods are the most significant techniques to evaluate and analyze, respectively, the distribution and the short- or long-term change of precipitation and temperature. Recently, several researchers have applied a linear trend $[33,40,41]$ and interpolation [42-44] in their study to assess climate change in a time series. The independent (time) and dependent (precipitation or temperature) variables are important variables. A simple linear regression was adopted to analyze the longterm trend of climate change in the HOA. In this study, a time series of annual mean precipitation and temperature were applied; however, some researchers studied mean monthly climate data [45].

Meteorological spatial interpolation is an estimation of weather or climate condition of unknown place from points scattered in a particular region, mostly precipitation and temperature data from hourly to annual scale. The reliability and accuracy of meteorological spatial interpolation depend on the quality of single data at a point, in addition to topography, building, atmospheric haze and circulation, and distance from the sea [46]; thus an overestimation or underestimation is considered as a limitation of interpolation [47, 48]. In ArcGIS, various methods are used to interpolate such as Interpolation Distance Weight (IDW), Kriging, natural neighbor, and spline. In this study, the natural neighbor interpolation is suitable to estimate the long-term or annual precipitation and temperature in the HOA, which is developed by Sibson, 1981 [49]. This method estimates the spatial value at the various location from the given scattered coordinates; for instance, the gridded meteorological values (Figure 1) are used to estimate the historical distribution of precipitation and temperature in the HOA. The natural neighbor interpolation is smooth and continuous to the value of its neighbor and it is commonly significant method, which is recently applied by some researchers [50, 51]. Although some modification was made in the weight of this method, for example, Gold, 1989 [52], the following equation is adopted in this study that was developed by Sibson:

$$
G(x, y)=\sum_{i=1}^{k} w i f(x, y),
$$

where $f(x, y)$ refers to the gridded points of observed weather stations and $G(x, y)$ is an estimated value in $(x, y)$ coordinate at weights value $(w i)$.
3.2. Standardized Precipitation Evapotranspiration Index (SPEI). Drought is considered as one of the most serious natural disasters in the world [53], particularly in the HOA, which is a direct indicator of climate change, caused by a deficiency of the summer rainfall and high rate of evapotranspiration. According to McKee et al., 1993 [54], and Rajsekhar et al., 2015 [55], a number of factors may be applied to define drought, generally, climate change, and particularly the seasonal weather changes such as metrological data, hydrological and water cycle, atmospheric and agricultural factors, or soil moisture. Although Palmer Drought Severity Index (PDSI) and Standardized Precipitation Index (SPI) are the most common methods to evaluate drought, a number of methods and models were developed to analyze the severity of drought, including Crop Moisture Index (CMI), Palmer Hydrological Drought Index (PHDI), the standardized precipitation evapotranspiration index (SPEI), Surface Water Supply Index (SWSI), Soil Moisture Deficit Index (SMDI), Evapotranspiration Deficit Index (ETDI), Vegetation Condition Index (VCI), and so forth [56]. Recently, several types of research used a new method to analyze drought; for instance, Sánchez et al., 2016 [57], integrated Soil Moisture Agricultural Drought Index (SMADI) with the Moderate Resolution Imaging Spectroradiometer (MODIS), NDVI, and Soil Moisture and Ocean Salinity (SMOS), Hao and AghaKouchak, 2013 [58], applied Multivariate Standardized Drought Index (MSDI), and Cammalleri et al., 2016 [59], combined Drought Severity Index (DSI) and water deficit magnitude and frequency.

In this study, the SPEI is applied to assess drought in the HOA. The standardized precipitation evapotranspiration index (SPEI) is a method used to analyze the condition of drought based on the water balance variations. VicenteSerrano et al., 2010 [56], introduced SPEI to quantify the dry and wet conditions at different time scales. Statistically, the SPEI is similar to SPI although it is complex that includes several variables such as precipitation, evapotranspiration, humidity, solar radiation, and wind speed, which are not easily available in meteorological data. Recently, several researchers have adopted the SPEI in their research [6064] to monitor and quantify drought. In this study, the Global SPEI database is applied to assess the drought condition of the HOA (http://sac.csic.es/spei/database.html\#p7). The Global SPEI database provides long-term drought conditions at a global scale with a spatial resolution of 0.5 degrees and the SPEI time-scale ranges between 1 and 48 months, covering from 1901 to 2014 . Here, we used gridded latitude and longitude of each station to download the monthly SPEI value for a 12-month SPEI from 1930 to 2014 and converted the monthly SPEI value into annual SPEI taking the average annual SPEI value to estimate the drought condition in this region. In this method, the potential evapotranspiration (PET) is the main parameter to calculate the water balance difference, which is the difference between precipitation and potential evapotranspiration (P - PET). Generally, the SPEI is calculated by the following formula [56]:

$$
\operatorname{PET}=16 K\left(\frac{10 T^{m}}{I}\right),
$$


TABLE 1: Drought category based on the SPEI value.

\begin{tabular}{lc}
\hline SPI value & Drought type \\
\hline 0 to -0.99 & Mild drought \\
-1 to -1.49 & Moderate drought \\
-1.5 to -1.99 & Severe drought \\
$\leq-2$ & Extreme drought \\
\hline
\end{tabular}

where $I$ refer to the heat index, the sum value of 12 months, $T$ is monthly temperature value, and " $m$ " and " $K$ " imply coefficient and correction coefficient, respectively.

$$
D_{i}=P_{i}-\mathrm{PET}_{i},
$$

where $D_{i}$ is the monthly water difference " $i$ " between $P_{i}$ and $\mathrm{PET}_{i}$.

However, at multiple timescales, a log-logistic distribution is required to standardize the accumulation of $D_{i}$ to estimate the SPEI, and the probability density in a threeparameter log-logistic distribution is defined as

$$
f(x)=\frac{\beta}{\alpha}\left(\frac{x-\gamma}{\alpha}\right)^{\beta-1}\left[1+\left(\frac{x-\gamma}{\alpha}\right)^{\beta}\right]^{-2},
$$

where $\beta, \alpha$, and $\gamma$ represent, respectively, shape, scale, and origin of parameters.

Therefore, the SPEI is defined as

$$
\text { SPEI }=W-\frac{C_{0}+C_{1} W+C_{2} W^{2}}{1+d_{1} W+d_{2} W^{2}+d_{3} W^{3}},
$$

where

$$
W=\sqrt{-2 \operatorname{In}(P)} \text { for } P \leq 0.5 .
$$

$P$ is the exceeding probability of the difference $(D)$ value; specifically $P=1-f(x)$. $P$ can be replaced by $1-P$ when $P>0.5$, and the sign of the resultant SPEI is reversed, and $C_{0}=2.515517, C_{1}=0.802853, C_{2}=0.010328, d_{1}=$ $1.432788, d_{2}=0.189269$, and $d_{3}=0.001308$.

For the detailed mathematical calculation of the SPEI it can be found in Vicente-Serrano et al., 2010 [56]. Generally, the value and category of the SPEI are the same as the SPI (Table 1), the negative SPEI value indicates dry climatic conditions while the positive SPEI value is for wet climatic conditions, and near-zero SPEI value shows normal climatic conditions $[62,64-66]$.

\section{Results}

4.1. Long-Term Spatial Interpolation Analysis. The spatial distribution of rainfall and temperature from 1930 to 2014 is explained in Figure 2. The spatial interpolation of the above two variables was completed from 48 stations selected for this study, overestimation or underestimation might have occurred in some regions. The highlands of Ethiopia and a small part of Kenya around the Lake Victoria received the highest rainfall $(>850 \mathrm{~mm})$; Eritrea, Djibouti, and Somalia had received the lowest rainfall $(<450 \mathrm{~mm})$ in the last 85 years. In the long-term interpolation, the highest temperature $\left(>25^{\circ} \mathrm{C}\right)$ was observed in eastern and western parts of Eritrea, Djibouti, Somalia, eastern and southern parts of Ethiopia, and central and northern parts around Lake Turkana of Kenya. In addition, the lowest temperature $\left(<19^{\circ} \mathrm{C}\right)$ was recorded in the highlands of Ethiopia and Eritrea, the southern part of Kenya.

4.2. Long-Term Trend and Anomaly Analysis. The long-term trend and anomaly of precipitation and temperature were assessed from 48 meteorological stations selected in this study. Figure 3 describes the trend and anomaly from 1930 to 2014. The result reveals that precipitation and temperature decreased and increased at a rate of $-0.3913 / \mathrm{yr}$. and $0.0084 / y r$., respectively, in the last 85 years. The trend of precipitation was insignificant at 95\% $(r=-0.158 P=0.148)$ but the trend was very significant for temperature at 99\% $(r=$ $\left.0.569 P=1.343 \times 10^{-8}\right)$. Relatively, the highest precipitation was recorded in $1961(875 \mathrm{~mm})$ and $1997(851 \mathrm{~mm})$ and the lowest amount of rainfall was observed in 1943, 1984, and 2009 , respectively, 576, 550, and $592 \mathrm{~mm}$ perhaps dry periods. Temperature dropped and it was very significant at 99\% ( $r=$ $-0.42 P=0.0068$ ) from 1930 to 1969 ; however, it appeared to rise dramatically between 1970 and 2014 and it was very significant at $99 \%\left(r=0.813 \mathrm{P}=2.77 * 10^{-11}\right)$. The annual mean temperature in the HOA declined by $-0.895^{\circ} \mathrm{C}$ from $1931\left(24.699^{\circ} \mathrm{C}\right)$ to $1968\left(23.804^{\circ} \mathrm{C}\right)$ and rose by $1.554^{\circ} \mathrm{C}$ from 1968 to $2009\left(25.356^{\circ} \mathrm{C}\right)$. Generally, the annual mean temperature increased approximately by $0.569^{\circ} \mathrm{C}$ between 1930 and 2014. Figure 3 explains the anomaly of precipitation and temperature in order to evaluate the warmest and coldest (temperature anomaly) or driest and wettest (precipitation anomaly) periods in the HOA in the past 85 years. The precipitation anomaly demonstrated normal climate condition observed in the HOA between 1930 and 2014. Generally, the anomaly value was detected between 50 and -50 with some extremely dry (negative) and wet (positive) periods, respectively, in 1943, 1984, and 2009 and in 1961, 1967, and 1997. In addition, the temperature anomaly revealed that the coldest (negative) and warmest (positive) climate condition were identified, respectively, between the 1930s-1980s and 1990s-2010s with the extreme coldest period in $1956\left(-0.71^{\circ} \mathrm{C}\right)$ and the warmest period in 2009 $\left(1.004^{\circ} \mathrm{C}\right)$.

Figure 4 demonstrates the composite SPEI anomaly for the wettest and driest years selected from 1930 to 1914. In this study, the positive and negative value of wet SPEI anomaly reveal regions that receive high and low rainfall, respectively, while the positive and negative value of dry SPEI anomaly illustrate areas that are very dry and less dry, respectively. Based on Figure 4, a large part of Eritrea, Kenya, southern and northern Ethiopia, and southern Somalia were the wettest regions whereas the western region of Ethiopia, Djibouti, southeast part of Eritrea, and northern Somalia received poor rainfall. The dry SPEI anomaly showed that aridity/dryness was high in most parts of Ethiopia, Eritrea, Kenya, and eastern and northern Somalia while low dryness was observed in northern and eastern Ethiopia, western Somalia, Djibouti, and a small part of Kenya. 

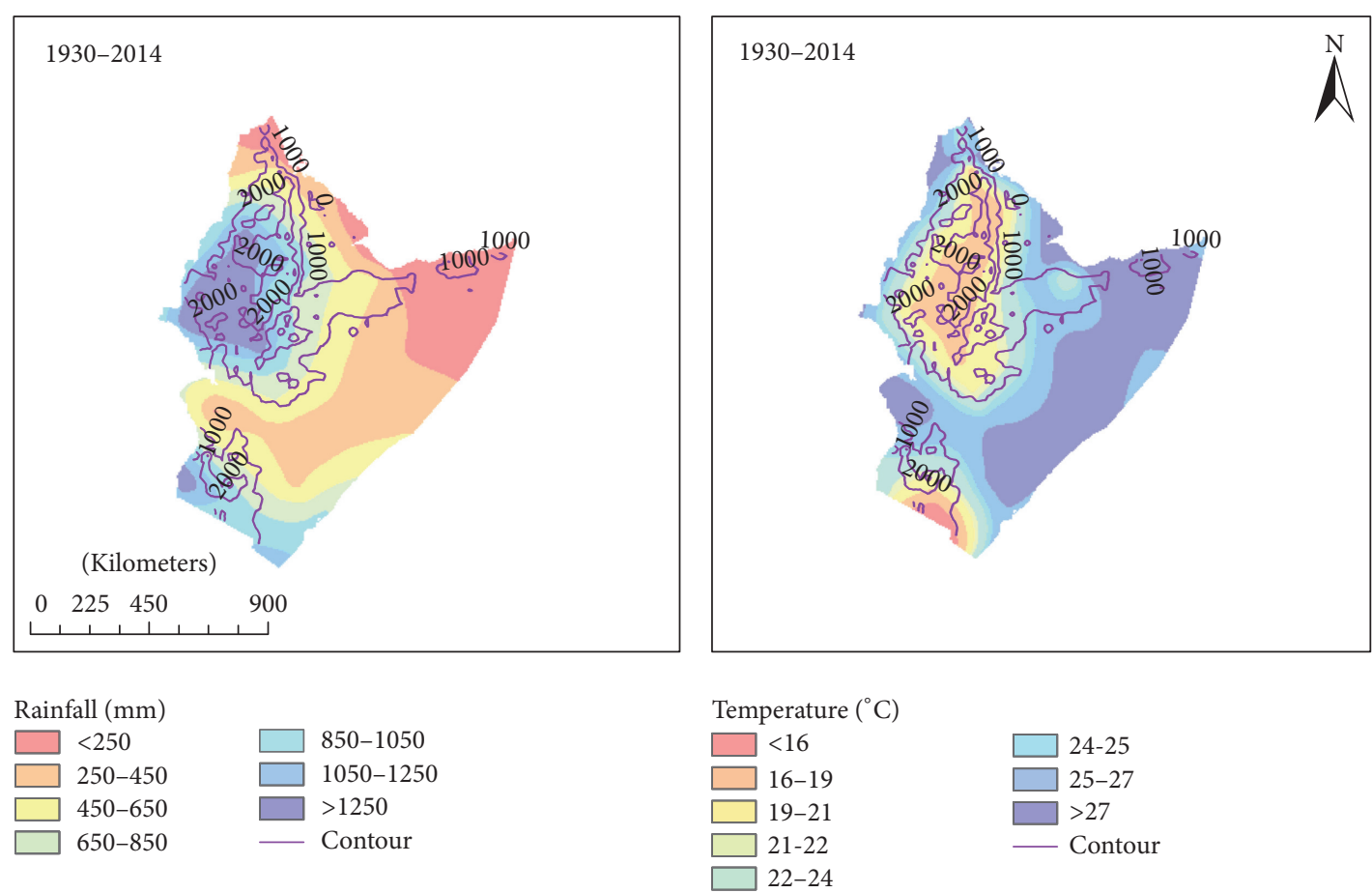

FIGURE 2: Long-term spatial interpolation of precipitation and temperature in the HOA.

4.3. Drought Assessment. Drought is directly or indirectly a response to the scarcity of rainfall. Usually, it occurs at local or regional scale and it is a devastating natural disaster of farmers in the HOA. Therefore, drought assessment and prediction are significant, particularly for farmers to prepare and establish a good plan to tackle the catastrophic effect of drought. Researchers and scientists have developed several indexes to analyze and predict drought. In this study, the SPEI is adopted to evaluate drought in the HOA from 1930 to 2014. The result revealed that moderate drought condition was detected in this region and severe to extreme drought was observed in 1943 and 1984. The drought was weakly identified using SPEI, particularly in the 1990s and 2000s; for instance, the SPEI value of 1991 and 2009 was -0.40 and -0.27 , respectively (Figure 5), despite significant record in HOA, particularly, in Ethiopia and Eritrea. Generally, drought is a severe environmental problem in the HOA in the last 85 years, particularly in the Eli Nino period.

Figure 6 illustrate the drought condition of the HOA from the SPEI possibly during the Eli Nino years. A drought is a natural event that commonly occurs on a local or regional scale; therefore, it is an irregular phenomenon in frequency, duration, and intensity in the HOA. For instance, in 1930, mild drought was recorded in large part of Eritrea, northwest of Ethiopia, and eastern Somalia, severe to extreme drought was observed (SPEI < -2.00) in 1943, 1953, 1965, 1984, 1991, and 1999, particularly in some regions of Eritrea and Ethiopia, and moderate to severe drought appeared in the other selected years at different regions of the HOA (Figure 6). Relatively, dryness was high in some regions of Kenya, Djibouti, and Somalia in 1939, 1943, 1959, and 1965; however, drought was serious in some parts of Ethiopia, Eritrea, and
Djibouti in 1971, 1991/9, 2004/9, and 2013. Generally, drought was a serious environmental disaster in the HOA from 1930 to 2014 .

\section{Discussion}

The results of this study demonstrated that in the past eight and a half decades climate change was active and serious environmental issue in the HOA. Rainfall was uneven and inconsistent in frequency and amount; the trend of the annual average precipitation and anomaly declined insignificantly from 1930 to 2014. Generally, approximately $72 \%$ of the HOA receives inadequate rainfall and approximately $89 \%$ of the region has moderate to very high temperature, particularly large part of Eritrea, Djibouti, and Somalia. However, the long-term mean annual temperature showed two contrary trends that temperature was significantly decreased from 1930 to the 1970 s at a rate of $-0.01 / y r$. and it was observed to increase very significantly since the 1970 s at a rate of $0.02 / y r$; thus, global warming is very high in this region due to high temperature and lower precipitation in the past few decades. Relatively, a large part of Somalia, Djibouti, Eritrea, and Ethiopia was under inadequate rainfall and high temperature while the highest amount of rainfall and the lowest temperature were recorded in the highlands of Ethiopia and southern Kenya (around the equator). The result of this work is consistent with previous studies in this region; for instance, Pricope et al., 2013 [29], found that rainfall decreased significantly in the Horn of Africa although his study excluded Eritrea and Djibouti. Generally, several researchers stated in their studies that rainfall declined in distribution, frequency, and amount/intensity in the HOA 

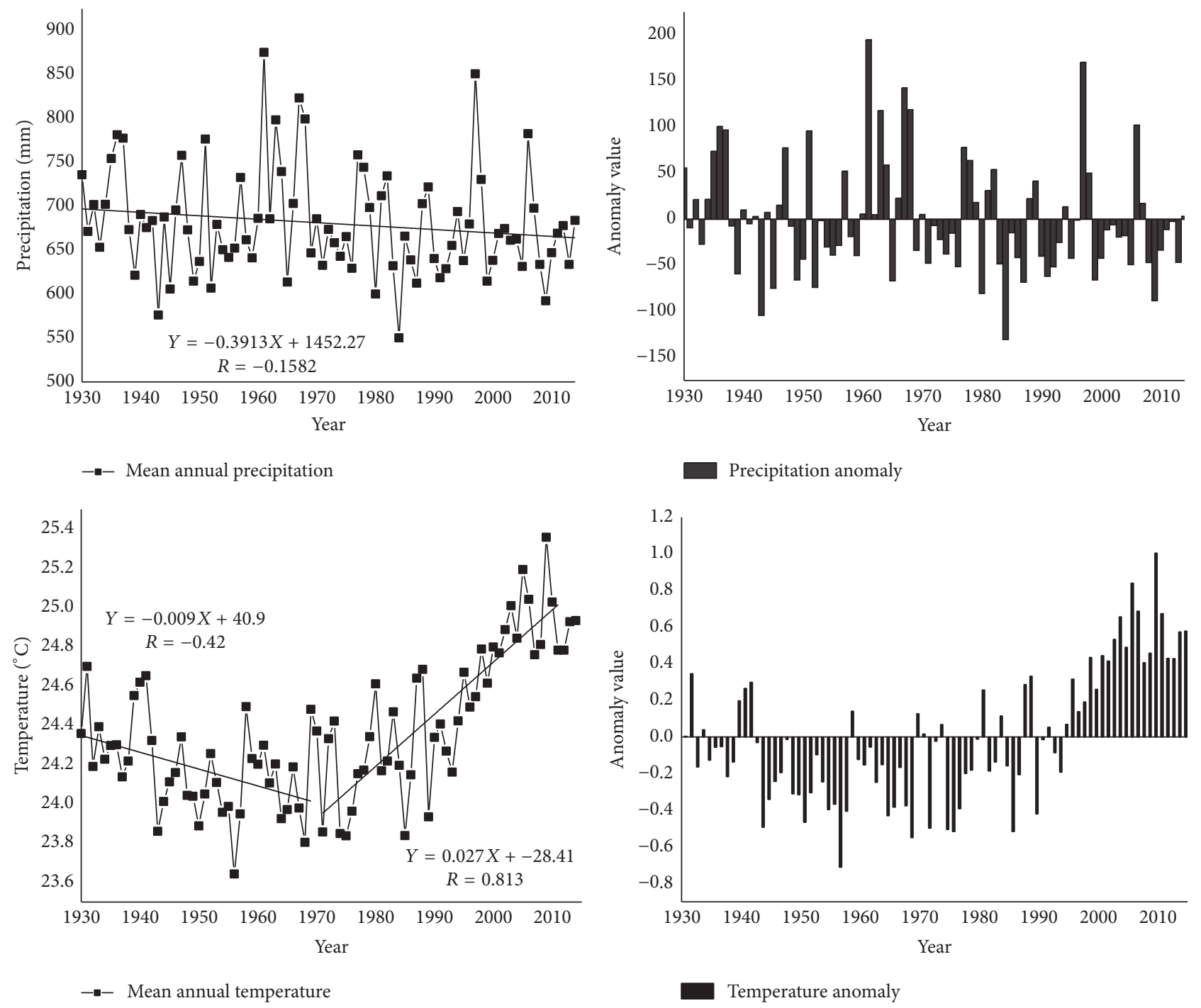

FIGURE 3: Long-term precipitation and temperature trend and anomaly (1930-2014) in the HOA.

[30, 67-72]. According to Frankl et al., 2013 [32], rainfall is inadequate and limited to the short rainy season in the HOA, especially in Ethiopia. The dramatic increase in the trend of the mean annual temperature since the 1970s is corresponding to other researchers in HOA [71]. Global warming due to climate change may accelerate food insecurity in the HOA. In this region, the farmers greatly depend on rain-fed agriculture; accordingly, they are suffering from poverty and hunger due to inadequate rainfall. Thus, poverty is extremely high in the HOA. According to FAO 2011 [73] and 2015 [10], it was reported that food insecurity is very high in this region because of severe drought.

Drought is a natural disaster that adversely affects agricultural and livestock production in Eastern Africa, particularly the HOA countries, including Somalia, Kenya, Ethiopia, Eritrea $[21,74,75]$. In this study, the SPEI revealed that drought was serious in the HOA from 1930 to 2014; generally, drought is a local or regional natural hazard; mild to moderate drought was recorded in the majority of the region but severe to extreme drought was observed in some regions. The severe to extreme droughts were detected in 1943 and 1984 and moderate drought appeared in 1991 and 2009. Relatively, the spatial distribution of drought was dominant around Kenya and southeast of Somalia in the 1930s, 1940s, and 1950s, it was a more serious environmental problem in Ethiopia, Eritrea, and Djibouti in the 1960s, 1970s, 2000s, and the 2010s, and it had adversely affected majority regions of Ethiopia and Eritrea. These results are consistent with previous studies in the Eastern Africa and in the Sahel region, according to Bhuvaneswari et al., 2013 [16], severe to extreme drought commonly occurs during the El Nino periods, and particularly the droughts in 1984, 1991, and 2009 are corresponding with previous researchers in the HOA and the Sahelian region [76-79]. In addition, Waal, 1991 [79], and Munro et al., 2008 [75], stated that drought adversely affected the HOA, particularly Ethiopia and Eritrea in 1973/4, 1984, and 1990/1. Drought is a direct impact of scarce rainfall but it might be intensified with human 


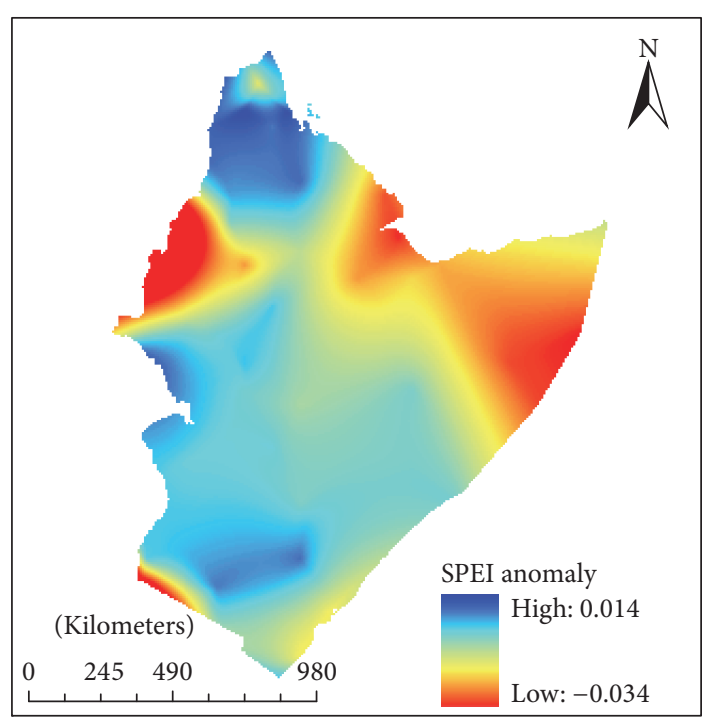

(a)

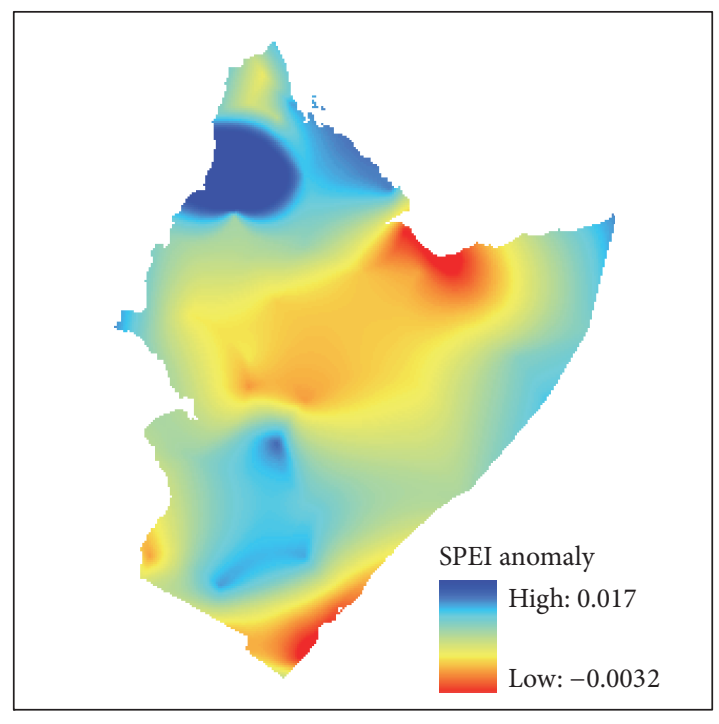

(b)

FIgURE 4: The composite SPEI anomaly of wettest (a) and driest (b) years in the HOA from 1930 to 2014.

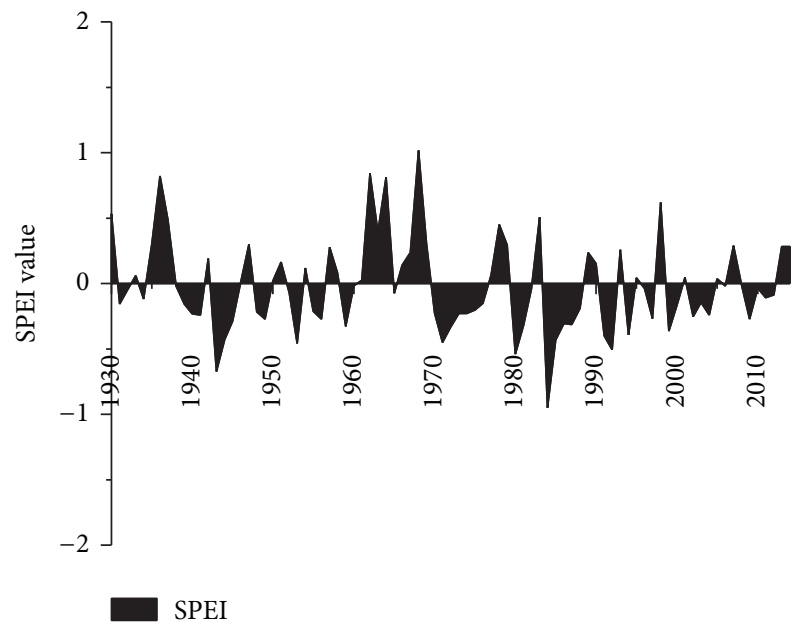

FIGURE 5: The drought condition of the HOA from SPEI.

activities as land degradation [69] including deforestation, desertification, erosion, and overcultivation extremely high in the HOA.

\section{Conclusion}

The long-term precipitation and temperature data were used as a proxy to assess climate change and drought in the HOA. Climate change was very active in this region in the past 85 years as statistically the trend of the mean annual precipitation and temperature declined and increased, respectively; in addition, drought is directly or indirectly the indicator of climate change where mild to moderate drought was observed throughout the study period with some severe to extreme drought, particularly during the El Nino periods. Aridity seems to be very high in the HOA because a large part of the region receives lower rainfall and is under high temperature, particularly Eritrea, Djibouti, and Somalia; however, in the highlands of Ethiopia and southern Kenya around the equator a considerable amount of rainfall was recorded. Poverty is extremely high in this region due to low crop and livestock production, which directly depends on rain-fed farming; besides, land degradation is significant as the demand for cultivation and firewood is growing with the increase of population; thus, climate change might be caused by the continuous low production of crop and livestock in the HOA. This study concluded that climate change and drought were very serious in the last eight and a half decades. Therefore, the adverse effect of climate change on agriculture might be minimized through the introduction of dry resistance crops and modifying the type of crops/seeds; for instance, replacing long growing season crops by short growing season crops and applying modern type of agriculture such as irrigation by constructing water reservoirs/dams may help to tackle food problems. Therefore, well preparation prior to El Nino periods is needed and increasing awareness of the people and encouragement may help to protect land degradation.

\section{Competing Interests}

The authors declare that there is no conflict of interests regarding the publication of this paper.

\section{Acknowledgments}

The National Science Foundation of China (Grant no. 41271024) supports this work. The authors thank Goush Fissehatsion and Wesley for helping in editing the language of our manuscript and our thanks are extended to the 

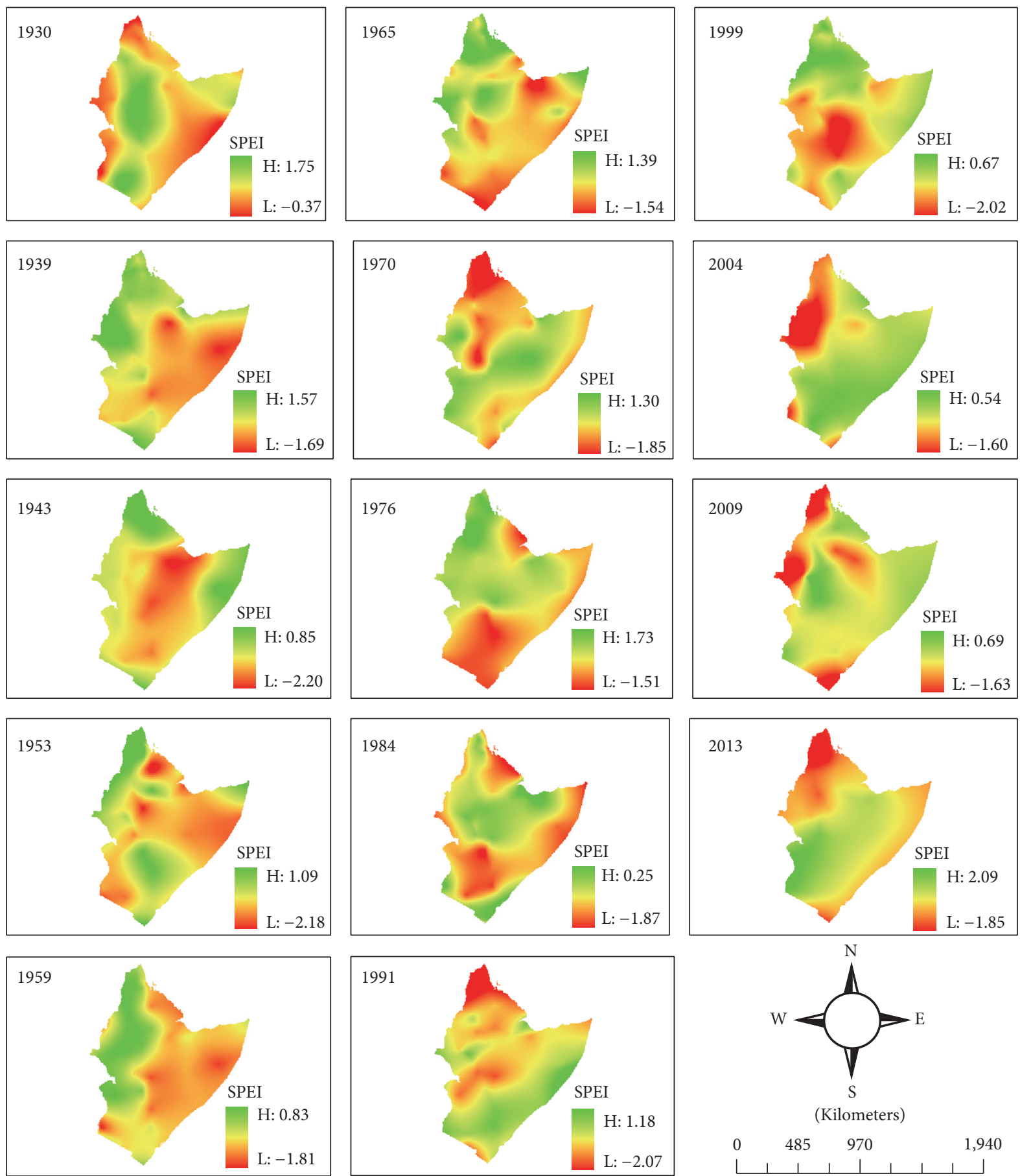

(Kilometers)

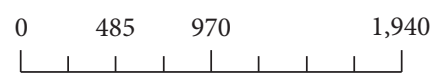

FIGURE 6: The drought condition of the HOA from SPEI probably during the selected Eli Nino years from 1930 to 2014.

Institute of Glaciology and Eco-Geography, College of Earth and Environmental Sciences, Lanzhou University, for their constructive efforts and comments to develop quality, clarity, and organization of this paper.

\section{References}

[1] T. Amjath-Babu, T. J. Krupnik, S. Aravindakshan, M. Arshad, and H. Kaechele, "Climate change and indicators of probable shifts in the consumption portfolios of dryland farmers in SubSaharan Africa: implications for policy," Ecological Indicators, vol. 67, pp. 830-838, 2016.

[2] IPCC, "Summary for policymakers," in Climate Change 2014: Impacts, Adaptation, and Vulnerability. Part A: Global and Sectoral Aspects, Contribution of Working Group II to the Fifth Assessment Report of the Intergovernmental Panel on Climate Change, C. B. Field, V. R. Barros et al., Eds., pp. 1-32, Cambridge University Press, Cambridge, UK, 2014. 
[3] V. Simonneaux, A. Cheggour, C. Deschamps, F. Mouillot, O. Cerdan, and Y. Le Bissonnais, "Land use and climate change effects on soil erosion in a semi-arid mountainous watershed (High Atlas, Morocco)," Journal of Arid Environments, vol. 122, pp. 64-75, 2015.

[4] H.-J. Xu and X.-P. Wang, "Effects of altered precipitation regimes on plant productivity in the arid region of northern China," Ecological Informatics, vol. 31, pp. 137-146, 2016.

[5] X. Yang, S. Liu, T. Yang et al., "Spatial-temporal dynamics of desert vegetation and its responses to climatic variations over the last three decades: a case study of Hexi region in Northwest China," Journal of Arid Land, vol. 8, no. 4, pp. 556-568, 2016.

[6] D. D. Houghton, Introduction to Climate Change: Lecture Notes for Meteorologists, WMO-No. 926, Secretariat of the World Meteorological Organization, Geneva, Switzerland, 2002.

[7] G. B. Tesfahunegn, K. Mekonen, and A. Tekle, "Farmers' perception on causes, indicators and determinants of climate change in northern Ethiopia: implication for developing adaptation strategies," Applied Geography, vol. 73, pp. 1-12, 2016.

[8] C. S. Hendrix and S. M. Glaser, "Trends and triggers: climate, climate change and civil conflict in Sub-Saharan Africa," Political Geography, vol. 26, no. 6, pp. 695-715, 2007.

[9] C. Huang, M. Zhang, J. Zou et al., "Changes in land use, climate and the environment during a period of rapid economic development in Jiangsu Province, China," Science of the Total Environment, vol. 536, pp. 173-181, 2015.

[10] FAO, Regional Overview of Food Insecurity: African Food Insecurity Prospects Brighter than Ever, FAO, Accra, Ghana, 2015.

[11] G. A. Kahsay and L. G. Hansen, "The effect of climate change and adaptation policy on agricultural production in Eastern Africa," Ecological Economics, vol. 121, pp. 54-64, 2016.

[12] D. Conway and E. L. F. Schipper, "Adaptation to climate change in Africa: challenges and opportunities identified from Ethiopia," Global Environmental Change, vol. 21, no. 1, pp. 227237, 2011.

[13] M. G. Ghebrezgabher, T. Yang, and X. Yang, "Remote sensing and GIS analysis of deforestation and desertification in central highland and eastern region of Eritrea (1972-2014)," International Journal of Sciences: Basic and Applied Research, vol. 18, no. 2, pp. 161-176, 2014.

[14] ADB, "Eastern Africa Regional Integration Strategy Paper 20112015," Regional Departments-East I \& East II (Orea/Oreb), September 2011, 2011.

[15] E. Gelcer, C. Fraisse, K. Dzotsi, Z. Hu, R. Mendes, and L. Zotarelli, "Effects of El Niño Southern Oscillation on the spacetime variability of Agricultural Reference Index for Drought in midlatitudes," Agricultural and Forest Meteorology, vol. 174-175, pp. 110-128, 2013.

[16] K. Bhuvaneswari, V. Geethalakshmi, A. Lakshmanan, R. Srinivasan, and N. U. Sekhar, "The impact of El Niño/Southern oscillation on hydrology and rice productivity in the Cauvery Basin, India: application of the soil and water assessment tool," Weather and Climate Extremes, vol. 2, pp. 39-47, 2013.

[17] J. Nyssen, J. Poesen, J. Moeyersons, J. Deckers, M. Haile, and A. Lang, "Human impact on the environment in the Ethiopian and Eritrean highlands-a state of the art," Earth-Science Reviews, vol. 64, no. 3-4, pp. 273-320, 2004.

[18] J. A. Tambo, "Adaptation and resilience to climate change and variability in north-east Ghana," International Journal of Disaster Risk Reduction, vol. 17, pp. 85-94, 2016.
[19] C. Jiang, D. Li, D. Wang, and L. Zhang, "Quantification and assessment of changes in ecosystem service in the Three-River Headwaters Region, China as a result of climate variability and land cover change," Ecological Indicators, vol. 66, pp. 199-211, 2016.

[20] Y. Zhang, S. Dong, Q. Gao et al., "Climate change and human activities altered the diversity and composition of soil microbial community in alpine grasslands of the Qinghai-Tibetan Plateau," Science of The Total Environment, vol. 562, pp. 353-363, 2016.

[21] A. AghaKouchak, "A multivariate approach for persistencebased drought prediction: application to the 2010-2011 East Africa drought," Journal of Hydrology, vol. 526, pp. 127-135, 2015.

[22] H. Fjelde and N. von Uexkull, "Climate triggers: rainfall anomalies, vulnerability and communal conflict in Sub-Saharan Africa," Political Geography, vol. 31, no. 7, pp. 444-453, 2012.

[23] J. W. Busby, T. G. Smith, and N. Krishnan, "Climate security vulnerability in Africa mapping 3.0 ", Political Geography, vol. 43, pp. 51-67, 2014.

[24] IES, "Institute for Environmental Security," 2011, http://www .envirosecurity.org/espa/.

[25] E. Van de Giessen, "Horn of Africa Environmental Security Assessment," Institute for Environmental Security, 2518 BC The Hague, The Netherlands, January 2011, http://www.envirosecurity.org/.

[26] M. G. Ghebrezgabher, T. Yang, X. Yang, X. Wang, and M. Khan, "Extracting and analyzing forest and woodland cover change in Eritrea based on Landsat data using supervised classification," The Egyptian Journal of Remote Sensing and Space Sciences, vol. 19, no. 1, pp. 37-47, 2016.

[27] J. Awange, M. S. Khandu, E. Forootan, and B. Heck, "Exploring hydro-meteorological drought patterns over the Greater Horn of Africa (1979-2014) using remote sensing and reanalysis products," Advances in Water Resources, vol. 94, pp. 45-59, 2016.

[28] S. Romahn, A. Mackensen, H. Kuhlmann, and J. Pätzold, "Benthic foraminiferal response to Late Glacial and Holocene sea level rise and rainfall variability off East Africa," Marine Micropaleontology, vol. 119, pp. 34-48, 2015.

[29] N. G. Pricope, G. Husak, D. Lopez-Carr, C. Funk, and J. Michaelsen, "The climate-population nexus in the East African Horn: emerging degradation trends in rangeland and pastoral livelihood zones," Global Environmental Change, vol. 23, no. 6, pp. 1525-1541, 2013.

[30] M. A. Maslin, C. M. Brierley, A. M. Milner, S. Shultz, M. H. Trauth, and K. E. Wilson, "East African climate pulses and early human evolution,” Quaternary Science Reviews, vol. 101, pp. 1-17, 2014.

[31] L. M. Kiage and K.-B. Liu, "Palynological evidence of climate change and land degradation in the Lake Baringo area, Kenya, East Africa, since AD 1650," Palaeogeography, Palaeoclimatology, Palaeoecology, vol. 279, no. 1-2, pp. 60-72, 2009.

[32] A. Frankl, J. Poesen, M. Haile, J. Deckers, and J. Nyssen, "Quantifying long-term changes in gully networks and volumes in dryland environments: the case of Northern Ethiopia," Geomorphology, vol. 201, pp. 254-263, 2013.

[33] S. M. Herrmann, A. Anyamba, and C. J. Tucker, "Recent trends in vegetation dynamics in the African Sahel and their relationship to climate," Global Environmental Change, vol. 15, no. 4, pp. 394-404, 2005.

[34] C. J. Willmott and K. Matsuura, "Terrestrial Air Temperature and Precipitation: Monthly and Annual Time Series 
(1900-2014)," Version 4.01, 2001, http://climate.geog.udel.edu/ $\sim$ climate/html_pages/README.ghcn_ts2.html.

[35] D. R. Easterling and T. C. Peterson, "The effect of artificial discontinuities on recent trends in minimum and maximum temperatures," Atmospheric Research, vol. 37, no. 1-3, pp. 19-26, 1995.

[36] D. Raes, P. Willems, and F. Gbaguidi, "RAINBOW-a software package for analysis data and testing the homogeneity of historical data and testing the homogeneity of historical data sets," in Proceedings of the 4th International Workshop on 'Sustainable Management of Marginal Drylands', pp. 27-31, Islamabad, Pakistan, 2006.

[37] J. Masanganise, B. Chipindu, T. Mhizha, E. Mashonjowa, and K. Basira, "An evaluation of the performance of global climate models (GCMs) for predicting temperature and rainfall in Zimbabwe," International Journal of Scientific and Research Publications, vol. 3, no. 8, pp. 1-11, 2013.

[38] Z. Al-Houri, A. Al-Omari, and O. Saleh, "Frequency analysis of annual one day maximum rainfall at amman zarqa basin," Civil and Environmental Research, vol. 6, no. 3, pp. 44-57, 2014.

[39] M. O. Kisaka, M. Mucheru-Muna, F. K. Ngetich, J. N. Mugwe, D. Mugendi, and F. Mairura, "Rainfall variability, drought characterization, and efficacy of rainfall data reconstruction: case of Eastern Kenya," Advances in Meteorology, vol. 2015, Article ID 380404, 16 pages, 2015.

[40] G. G. Matishov, S. L. Dzhenyuk, D. V. Moiseev, and A. P. Zhichkin, "Trends in hydrological and ice conditions in the Large Marine Ecosystems of the Russian Arctic during periods of climate change," Environmental Development, vol. 17, supplement 1, pp. 33-45, 2015.

[41] R. R. Heim, "An overview of weather and climate extremesproducts and trends," Weather and Climate Extremes, vol. 10, pp. 1-9, 2015.

[42] W. Suparta and R. Rahman, "Spatial interpolation of GPS PWV and meteorological variables over the west coast of Peninsular Malaysia during 2013 Klang Valley Flash Flood," Atmospheric Research, vol. 168, pp. 205-219, 2016.

[43] B. Buongiorno Nardelli, R. Droghei, and R. Santoleri, "Multidimensional interpolation of SMOS sea surface salinity with surface temperature and in situ salinity data," Remote Sensing of Environment, vol. 180, pp. 392-402, 2016.

[44] M. Kilibarda, M. Tadić, T. Hengl, J. Luković, and B. Bajat, "Global geographic and feature space coverage of temperature data in the context of spatio-temporal interpolation," Spatial Statistics, vol. 14, pp. 22-38, 2015.

[45] S. B. Ogungbenro and T. E. Morakinyo, "Rainfall distribution and change detection across climatic zones in Nigeria," Weather and Climate Extremes, vol. 5-6, pp. 1-6, 2014.

[46] A. Irmak, P. K. Ranade, D. Marx et al., "Spatial interpolation of climate variables in Nebraska," Transactions of the ASABE, vol. 53, no. 6, pp. 1759-1771, 2010.

[47] L. Gottschalk, I. Krasovskaia, E. Dominguez, F. Caicedo, and A. Velasco, "Interpolation of monthly runoff along rivers applying empirical orthogonal functions: application to the Upper Magdalena River, Colombia," Journal of Hydrology, vol. 528, pp. 177191, 2015.

[48] C. C. F. Plouffe, C. Robertson, and L. Chandrapala, "Comparing interpolation techniques for monthly rainfall mapping using multiple evaluation criteria and auxiliary data sources: a case study of Sri Lanka," Environmental Modelling and Software, vol. 67, pp. 57-71, 2015.
[49] R. Sibson, "A brief description of natural neighbor interpolation," in Interpreting Multivariate Data, V. Barnett, Ed., vol. 36, chapter 2, p. 21, John Wiley \& Sons, New York, NY, USA, 1981.

[50] J. Meersmans, K. Van Weverberg, S. De Baets et al., "Mapping mean total annual precipitation in Belgium, by investigating the scale of topographic control at the regional scale," Journal of Hydrology, vol. 540, pp. 96-105, 2016.

[51] J.-D. Boissonnat and F. Cazals, "Natural neighbor coordinates of points on a surface," Computational Geometry, vol. 19, no. 2-3, pp. 155-173, 2001.

[52] C. M. Gold, "Surface interpolation, spatial adjacency and GIS," Three dimensional applications in GIS, pp. 21-35, 1989.

[53] B. Narasimhan and R. Srinivasan, "Development and evaluation of Soil Moisture Deficit Index (SMDI) and Evapotranspiration Deficit Index (ETDI) for agricultural drought monitoring," Agricultural and Forest Meteorology, vol. 133, no. 1-4, pp. 69-88, 2005.

[54] T. B. McKee, N. J. Doesken, and J. Kleist, "The relationship of drought frequency and duration to time scales," in Proceedings of the 8th Conference on Applied Climatology, pp. 17-22, Anaheim, Calif, USA, 1993.

[55] D. Rajsekhar, V. P. Singh, and A. K. Mishra, "Multivariate drought index: an information theory based approach for integrated drought assessment," Journal of Hydrology, vol. 526, pp. 164-182, 2015.

[56] S. M. Vicente-Serrano, S. Beguería, and J. I. López-Moreno, "A multiscalar drought index sensitive to global warming: the standardized precipitation evapotranspiration index," Journal of Climate, vol. 23, no. 7, pp. 1696-1718, 2010.

[57] N. Sánchez, Á. González-Zamora, M. Piles, and J. MartínezFernández, "A new Soil Moisture Agricultural Drought Index (SMADI) Integrating MODIS and SMOS Products: a case of study over the iberian Peninsula," Remote Sensing, vol. 8, no. 4, article no. 287, 2016.

[58] Z. Hao and A. AghaKouchak, "Multivariate standardized drought index: a parametric multi-index model," Advances in Water Resources, vol. 57, pp. 12-18, 2013.

[59] C. Cammalleri, F. Micale, and J. Vogt, "A novel soil moisturebased drought severity index (DSI) combining water deficit magnitude and frequency," Hydrological Processes, vol. 30, no. 2, pp. 289-301, 2016.

[60] Y. Zhang, Q. You, H. Lin, and C. Chen, "Analysis of dry/wet conditions in the Gan River Basin, China, and their association with large-scale atmospheric circulation," Global and Planetary Change, vol. 133, pp. 309-317, 2015.

[61] R. C. Deo and M. Şahin, "Application of the Artificial Neural Network model for prediction of monthly standardized precipitation and evapotranspiration index using hydrometeorological parameters and climate indices in Eastern Australia," Atmospheric Research, vol. 161-162, pp. 65-81, 2015.

[62] C. Tan, J. Yang, and M. Li, "Temporal-spatial variation of drought indicated by SPI and SPEI in Ningxia Hui Autonomous Region, China," Atmosphere, vol. 6, no. 10, pp. 1399-1421, 2015.

[63] C. M. Gouveia, R. M. Trigo, S. Beguería, and S. M. VicenteSerrano, "Drought impacts on vegetation activity in the Mediterranean region: an assessment using remote sensing data and multi-scale drought indicators," Global and Planetary Change, 2016.

[64] X. Li, B. He, X. Quan, Z. Liao, and X. Bai, "Use of the Standardized Precipitation Evapotranspiration Index (SPEI) to characterize the drying trend in Southwest China from 19822012," Remote Sensing, vol. 7, no. 8, pp. 10917-10937, 2015. 
[65] X. Liu, S. Wang, Y. Zhou, F. Wang, W. Li, and W. Liu, "Regionalization and spatiotemporal variation of drought in China based on standardized precipitation evapotranspiration index (1961-2013)," Advances in Meteorology, vol. 2015, Article ID 950262, 18 pages, 2015.

[66] K. Venkataraman, S. Tummuri, A. Medina, and J. Perry, "21st century drought outlook for major climate divisions of Texas based on CMIP5 multimodel ensemble: implications for water resource management," Journal of Hydrology, vol. 534, pp. 300316, 2016.

[67] M. Dawelbait and F. Morari, "Monitoring desertification in a Savannah region in Sudan using Landsat images and spectral mixture analysis," Journal of Arid Environments, vol. 80, pp. 4555, 2012.

[68] J. Verdin, C. Funk, G. Senay, and R. Choularton, "Climate science and famine early warning," Philosophical Transactions of the Royal Society B: Biological Sciences, vol. 360, no. 1463, pp. 2155-2168, 2005.

[69] J. Nyssen, A. Frankl, M. Haile et al., "Environmental conditions and human drivers for changes to north Ethiopian mountain landscapes over 145years," Science of the Total Environment, vol. 485-486, no. 1, pp. 164-179, 2014.

[70] L. Hein, N. de Ridder, P. Hiernaux, R. Leemans, A. de Wit, and M. Schaepman, "Desertification in the Sahel: towards better accounting for ecosystem dynamics in the interpretation of remote sensing images," Journal of Arid Environments, vol. 75, no. 11, pp. 1164-1172, 2011.

[71] P. Gonzalez, C. J. Tucker, and H. Sy, "Tree density and species decline in the African Sahel attributable to climate," Journal of Arid Environments, vol. 78, pp. 55-64, 2012.

[72] V. J. Terwilliger, Z. Eshetu, Y. Huang, M. Alexandre, M. Umer, and T. Gebru, "Local variation in climate and land use during the time of the major kingdoms of the Tigray Plateau in Ethiopia and Eritrea," Catena, vol. 85, no. 2, pp. 130-143, 2011.

[73] FAO, "Drought Emergencies in the Horn of Africa," 2011, http:// www.fao.org/fileadmin/templates/tc/tce/pdf/Executive_Briefs/ 02.02.12_Issue_10_HoA_FAOEB.pdf.

[74] M. Ahmed, M. Sultan, J. Wahr, and E. Yan, "The use of GRACE data to monitor natural and anthropogenic induced variations in water availability across Africa," Earth-Science Reviews, vol. 136, pp. 289-300, 2014.

[75] R. N. Munro, J. Deckers, M. Haile, A. T. Grove, J. Poesen, and J. Nyssen, "Soil landscapes, land cover change and erosion features of the Central Plateau region of Tigrai, Ethiopia: photomonitoring with an interval of 30 years," Catena, vol. 75, no. 1 , pp. 55-64, 2008.

[76] M. Brandt, C. Romankiewicz, R. Spiekermann, and C. Samimi, "Environmental change in time series-an interdisciplinary study in the Sahel of Mali and Senegal," Journal of Arid Environments, vol. 105, pp. 52-63, 2014.

[77] E. Teferi, W. Bewket, S. Uhlenbrook, and J. Wenninger, "Understanding recent land use and land cover dynamics in the source region of the Upper Blue Nile, Ethiopia: spatially explicit statistical modeling of systematic transitions," Agriculture, Ecosystems and Environment, vol. 165, pp. 98-117, 2013.

[78] R. Hessel, J. van den Berg, O. Kaboré et al., "Linking participatory and GIS-based land use planning methods: a case study from Burkina Faso," Land Use Policy, vol. 26, no. 4, pp.1162-1172, 2009.

[79] A. D. Waal, "Thirty years of war and famine in Ethiopia. Evil days," African Watch Report, Human Rights Watch, New York, NY, USA, 1991. 

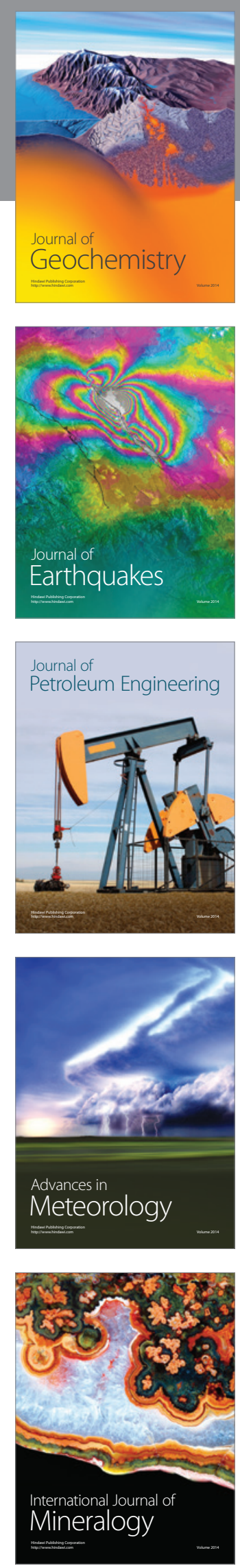
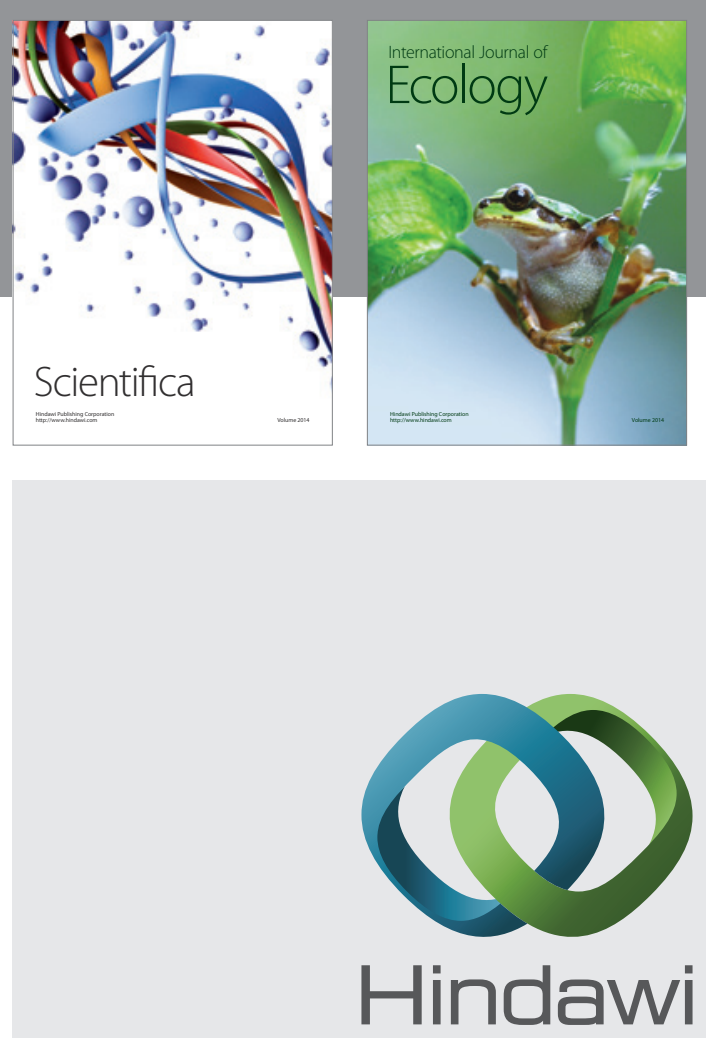

Submit your manuscripts at

http://www.hindawi.com
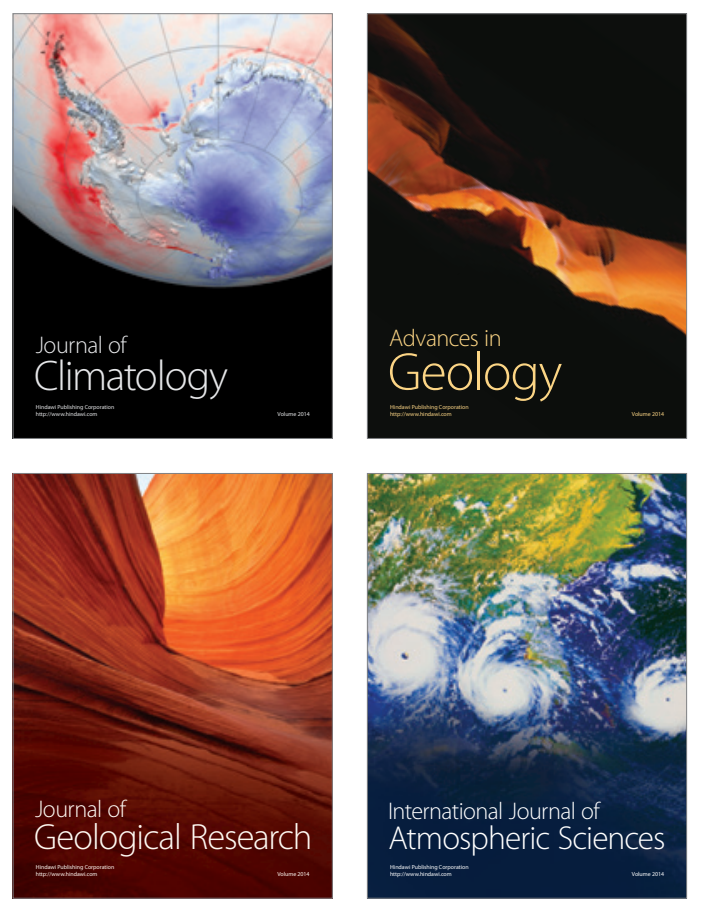

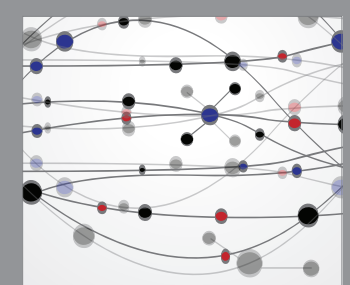

The Scientific

\section{World Journal}
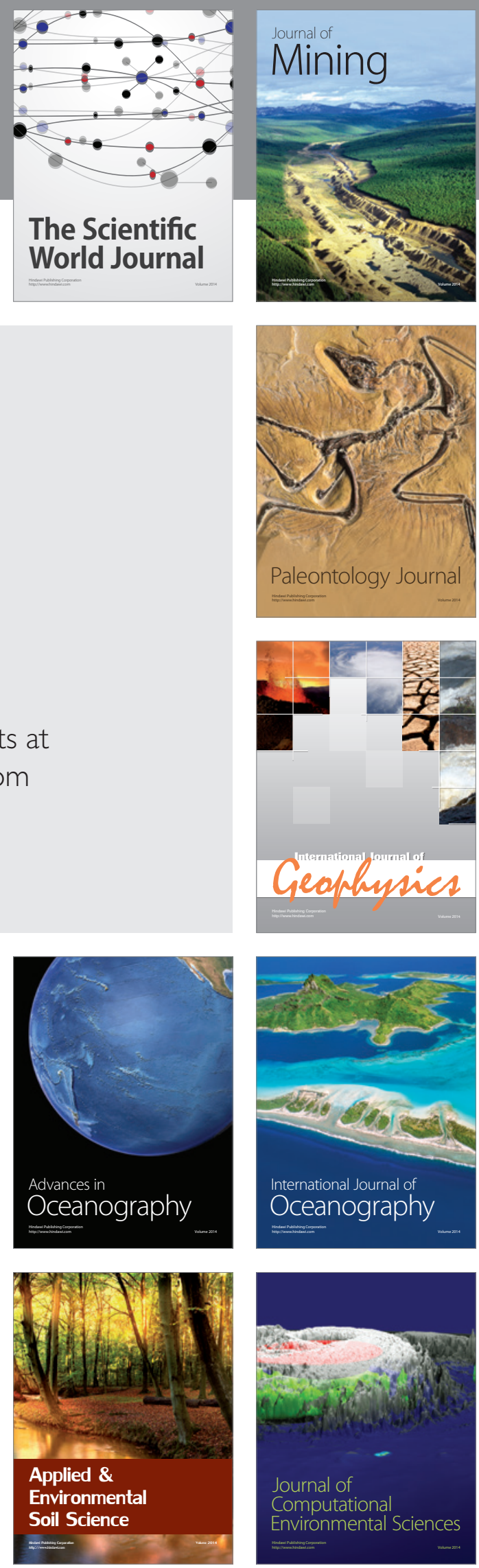